\title{
Comic-Con: Can Comics of the Constitution Enable Meaningful Learning in Political Science?
}

Katharine A. Owens, University of Hartford

Victor Eno, Florida Agricultural and Mechanical University

Jocelyn Abrams, University of Hartford

Danielle Bedney, University of Hartford

ABSTRACT This article explores the value and application of using comic images to teach difficult political texts. We presented either visual or textual portions of the Constitution to 71 American 18- to 22-year-olds using Survey Monkey Audience, measuring and comparing their knowledge of the Constitution before and after viewing. Respondents viewing the comic of congressional duties experienced statistically significant gains in pretest to posttest mean knowledge scores. Respondents viewing the text also experienced an increase in mean scores pretest to posttest; however, these changes were smaller and not statistically significant. This indicates that students may better comprehend content from visual depictions of difficult texts. We conclude by providing an example of one way that we use comics of political texts as a tool for student learning in an international civics exchange program.

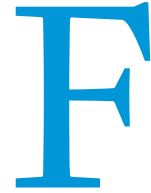
oundational documents such as the Declaration of Independence and the US Constitution can provide important insight into the structure and function of American government. Yet, these texts can be difficult for college students to read and comprehend. The style in which the Constitution is written at times obfuscates its meaning for students. Whereas faculty may see the value of introducing primary documents, frustrated students may quickly give up on difficult material. The goals of this article are twofold: (1) to understand whether a visual depiction of the Constitution might help a reader digest this difficult text, and (2) to briefly share one way that we use this method in the classroom. This article highlights how arts-based learning-particularly visual images elucidating content-may be a powerful tool to help students understand difficult political documents.

\section{BACKGROUND}

By exploring the literature on knowledge and engagement, artsbased learning, and comics in the classroom, we can better understand how previous work on these topics fuels this research.

Katharine A. Owens $(D)$ is associate professor in politics, economics, and international studies at the University of Hartford. She can be reached at kowens@hartford.edu. Victor Eno is associate professor of political science at Florida Agricultural and Mechanical University. He can be reached at victor.eno@famu.edu.

Jocelyn Abrams and Danielle Bedney are students at the University of Hartford.

\section{Linking Knowledge and Engagement}

Understanding the way government works is critical to becoming an active participant. A 1999 study of civic knowledge and behavior of 14-year-olds in 28 countries found that the respondents had fundamental, albeit shallow, knowledge about politics and government (Torney-Purta et al. 2001). The authors wrote that, excluding voting, many students do not find political engagement important, noting that they would be "unlikely to join a political party, [to] consider writing a letter to a newspaper about a social concern, or [to] become a political candidate in the future" (Torney-Purta et al. 2001, 180). A 2009 update of this study included 38 countries and demonstrated a decline in civic knowledge in nearly half of the 15 countries that were a part of both studies (Schulz et al. 2010). In addition, voting participation is low among youth: the Center for Information and Research on Civic Learning and Engagement (2016) reported that approximately 50\% of eligible 18- to 29-yearold US citizens voted in the 2016 presidential election. In research on youth in the United Kingdom, Sloam (2008) emphasized the important role that political science education plays in rejuvenating political engagement. Although not the goal of this study, political participation is a public good that is critical to creating inclusive and representative democratic government.

\section{Arts-Based Learning}

Arts-based education is one promising method of involving a range of learners on social topics (Clover 2000; Curtis 2011; 
Curtis, Reid, and Reeve 2014; Dewhurst 2011; Graham 2007; Lawrence 2005). Education that utilizes the arts respects multiple ways of knowing and has the potential to more fully and more creatively explore topics, thereby allowing for the development of deeper knowledge (Curtis, Reid, and Reeve 2014; Dewhurst 2011; Graham 2007; Lawrence 2005). Arts-based learning or visual learning may be used in combination with other modes in the classroom. Universal Design for Learning (UDL) is "a framework to improve and optimize teaching and learning for all people based on scientific insights into how humans learn" (CAST 2019). Proponents of UDL posit that accessing material in multiple ways (e.g., visual, audial, and tactile) supports more student learning styles (Schreiner, Rothenberger, and Sholtz 2013). Frey and Fisher $(\mathbf{2 0 0 8}, \mathbf{1})$ noted that "visually literate learners... make connections, determine importance, synthesize information, evaluate, and critique" and, when combined with text, this yields a "more complete understanding" of material. Visual or arts-based learning is one tool that faculty can use to captivate students and improve learning. she emphasized the importance of student-teacher interaction and discussion of the concept cartoon.

Researchers in a range of disciplines use visual imagery-if not specifically concept cartoons-to engage students. Tatalovic (2009) reviewed the use of comics in the sciences and found that they have been successfully employed since the nineteenth century to explain scientific principles to both students and the public. Park, Kim, and Chung (2011) combined humor and content, creating comics to enhance anatomy lectures at the Ajou University School of Medicine in Korea. According to a 2010 study based in Turkey, effective cartooning in the classroom improves instruction, supports active learning, enables critical thinking, and may play a role in higher academic achievement (Birisci, Metin, and Karakas 2010). Williams $(2008,13)$ found that comics in particular can assist in "crossing boundaries, creating empathy, and educating students about the artistic production and consumption of powerful texts." Investigating the use of comic books to teach science to non-majors, Hosler and Boomer (2011) reported statistically significant gains among this group's content knowledge,

\section{According to a 2010 study based in Turkey, effective cartooning in the classroom improves instruction, supports active learning, enables critical thinking, and may play a role in higher academic achievement (Birisci, Metin, and Karakas 2010).}

\section{Comics in the Classroom}

The use of comics in the classroom is not new. Many educators use humorous cartoons to lighten lectures or teach topics in a fun and engaging way (Park, Kim, and Chung 2011). Much of the research on learning via images stems from the field of concept cartoons. Concept cartoons are not humorous panels about a topic-political or otherwise-but rather most often a visual depiction of a scientific concept that features one correct conceptualization and common alternate but incorrect conceptualizations (Akamca, Ellez, and Hamurcu 2009; Keogh and Naylor 1999). Expressed another way, concept cartoons depict a group of students puzzling out explanations for observed phenomena. Only one correct answer exists for each concept cartoon. In this way, concept cartoons help students explore and think through correct and incorrect answers to a question, ruminating on why they may be right or wrong. An example from the field of chemistry shows a group of students asking why nails rust (Millgate House Education 2014). They give alternate explanations-one student posits that a nail will not rust in the cold; another claims that a wet nail will rust; a third surmises that contact with other rusty nails will cause a nail to rust; and a fourth student infers that a nail will not rust when under water (Millgate House Education 2014). Rusting happens when both air and water are present; therefore, the correct answer is that a wet nail will rust (Millgate House Education 2014). Students explored the options presented in the concept cartoon to understand the concept. In a study combining quantitative and qualitative methods to assess science learning of fourth-graders, Akamca, Ellez, and Hamurcu (2009) found that concept cartoons positively affect student achievement. Keogh and Naylor (1999) reported that concept cartoons support learning through enabling discussion and supporting inquiry. Kabapinar (2005) wrote that, among other results, teaching through the use of concept cartoons resolves student misconceptions on content; however, attitudes about biology, and attitudes about comics. Using comics and cartoons to teach algebraic concepts, Toh (2009) noted that they allow teachers to engage students, yielding increases in motivation. In working with college-level engineering students, Wylie and Neely (2016) observed that the use of comics allows students to retain knowledge of complex concepts. Political science faculty at many levels use comics and visual images to teach. It is not uncommon to employ political or editorial cartoons in the politics classroom as tools to elucidate ideas, share political opinion, review political history, and teach critical and analytical thinking (Dougherty 2002; Owens 2016). Using photographs and paintings to teach the first amendment to $\mathrm{K}-12$ students, LeCompte and Bauml (2012) found this method most beneficial for Englishas-a-Second-Language (ESL) and younger students. Editorial cartoons even may have a positive impact on political participation (Baumgartner 2008). In these ways, many disciplines recognize the value of using comics to stimulate learning and engagement, although their use is most prominent in STEM fields.

Despite the breadth of research on how faculty use visual images to teach content, there are few assessments of the comparative effectiveness of visual versus written material. In an analysis of knowledge gains through text versus a multimedia display (i.e., audio, video, animation, graphics, text, and special effects), Hallett and Faria (2006) observed stronger gains in recalled content through the use of multimedia. In a study that compared the ability of students to transfer problem-solving performance (i.e., apply information learned from one problem to a new problem), Mayer $(1997,10)$ reported that students with combined visual and text explanations yielded a median of " $65 \%$ more creative solutions" than those having a text-only explanation. Focusing on studies of general-education political science courses, Ulbig (2009, 385) found that visuals "enhance students' impressions of the discipline... and boost their interest in and knowledge of 
politics and public affairs" as well as "enhance students' classroom experiences... [and] global impressions of the course" (Ulbig 2010, 185). This evidence suggests that visual images are compelling and effective; however, researchers have not yet made a direct analysis of comparative knowledge gains from text and visual images.
Seven respondents quit after answering the first five questions but before viewing an image or text. Nineteen passed beyond this point, viewing either the text (12) or the comic (7) before deciding to quit. Of interest, more respondents quit after viewing the text than the comic. Exposure to the text or the comic was randomly

\section{This evidence suggests that visual images are compelling and effective; however, researchers have not yet made a direct analysis of comparative knowledge gains from text and visual images.}

This research seeks to fill the gap on the comparative benefits of visual versus textual content. We assessed a group of 71 American 18- to 22-year-olds to understand the knowledge gains they experienced from viewing a visual depiction of a portion of the Constitution, and we share how we used this method to teach foundational documents to students in an international civics exchange program.

\section{METHODOLOGY}

We used the Survey Monkey Audience feature to administer the study May 8-17, 2018. Survey Monkey Audience rewards volunteer respondents for participating in online surveys not with payment but rather by donating 50 cents per survey to a charity selected by the respondent (Survey Monkey Audience 2019). Although this yields a self-selected population, it is not significantly different from college-age populations used for much psychological research, who must participate in surveys for credit in introductory psychology courses. Survey Monkey Audience participants are not inundated with questionnaires and "take regular self-profiling surveys" to ensure their personal information is up to date (Survey Monkey 2019, 1). The sample was restricted to responses from a college-age population: American 18- to 22-yearolds; however, we did not require that respondents be registered as college students, had taken any college courses, or were college graduates. In this way, the sample included college-age students but not necessarily college students. Of the 97 respondents who began the survey, only 71 completed it. The results available from Survey Monkey Analysis do not have the capacity to demonstrate whether there is a significant difference between those who did and did not complete the survey. For all participants, the survey began with a series of five questions about the Constitution (appendix A). Respondents then viewed either the text (appendix B) or the comic (appendix C) with the following instructions:

- TEXT: Please read the following text, which describes the duties of members of Congress.

- COMIC: Please spend a few minutes viewing the following comic, which describes some of the duties of members of Congress.

Afterwards, all respondents were directed to answer the five questions again. The questions included three about the duties of Congress as laid out in the Constitution $\left(Q_{2}-4\right)$, one about the Supreme Court (Q1), and one about the role of the president $\left(\mathrm{Q}_{5}\right)$. The comic and text only addressed constitutional duties of Congress. The topics of the congressional-duty questions were covered in both the text and the comics. assigned. Question order was the same for all respondents in both pretests and posttests.

When considering knowledge gained from viewing comics versus text, we expected the scores of participants who viewed the comic to improve more than those who viewed the text. In addition, we expected no significant change in pretest to posttest scores for questions about the Supreme Court (Q1) and the role of the president $\left(\mathrm{Q}_{5}\right)$, whereas we expected to see a change in questions focused on congressional duties $\left(Q_{2}, Q_{3}, Q_{4}\right)$.

\section{RESULTS AND ANALYSIS}

This section describes the sample population by treatment (i.e., exposure to text or comic from the Constitution). The parameters we entered into Survey Monkey Analysis were to isolate a college-age population, 18 to 22 years old. However, none of the respondents who shared their age were 18 years old. Table 1 shows the distribution of age among participants, including the percentage of the total for that category (i.e., comic or text).

Table 2 shows the distribution of gender among participants, including the percentage of the total for that category (i.e., comic or text). Survey Monkey does not have a nonbinary option for gender.

Table 3 shows the distribution of income brackets among participants, including the percentage of the total for that category (i.e., comic or text).

Table 1

Age of Respondents

\begin{tabular}{lcc} 
Age & Comic ( $\mathbf{n = 4 2 )}$ & Text (n=29) \\
\hline 19 & $6(14 \%)$ & $6(21 \%)$ \\
\hline 20 & $7(17 \%)$ & $5(17 \%)$ \\
\hline 21 & $11(26 \%)$ & $6(21 \%)$ \\
\hline 22 & $5(12 \%)$ & $2(7 \%)$ \\
\hline Did not respond & $13(31 \%)$ & $10(34 \%)$ \\
\hline
\end{tabular}

Table 2

Gender of Respondents

\begin{tabular}{lcc}
$\mathbf{( n = 7 0 )}$ & Comic $(\boldsymbol{n}=\mathbf{4 1 )}$ & Text $(\boldsymbol{n}=\mathbf{2 9})$ \\
\hline Female & $29(71 \%)$ & $25(86 \%)$ \\
\hline Male & $12(29 \%)$ & $4(14 \%)$ \\
\hline
\end{tabular}


In all cases, the groups are not matched but rather represent comparable samples. As described previously, respondents were asked five questions on content of the Constitution; shown either text or a comic about congressional duties; and then asked the same five questions again. Respondents were given one point for each correct answer; these scores were totaled to create pretest and posttest scores. We used a simple t-test to analyze the means of pretest and posttest scores of the sample. We set significance at the 0.05 level; assuming that scores would increase between preand post-analysis for all groups, we used a 1-tailed test. Results are shown in table 4 . was youth who viewed the text and their response to the question about the Supreme Court. This value decreased from pretest to posttest, although not such that it was statistically significant. In all other cases, there was an increase; however, the only increase that was statistically significant is for youth who saw the comic in their responses to questions about congressional duties $(t(41)=1.87, p=0.034)$. This supports our hypothesis that visual images aid student understanding of complex content. Although these results support our hypothesis, further study is needed to replicate these results and to understand under what conditions this pattern does or does not hold true.

\section{This analysis of 71 American 18- to 22-year-olds indicates that youth gain more knowledge when they view a comic panel of the Constitution than they do from reading the text of the document.}

Of the 71 young people who completed the survey, 42 saw the comic and 29 saw the text. Scores increased for both groups between the pretest and posttest, although youth who saw the comic increased more and the difference in their pretest and posttest was statistically significant $(\mathrm{t}(41)=2.29, \mathrm{p}=0.0136)$. This indicates support for the use of comics to reinforce comprehension of difficult texts.

Not all of the survey questions focused on the content of the comics and text; therefore, it is important to understand how student scores compared when considering questions about congressional duties. Table 5 isolates questions by content to better understand any potential changes. In almost all cases, there was an increase in mean scores from pretest to posttest. The exception

Table 3

Income of Respondents

\begin{tabular}{lcc}
$(\mathbf{n}=\mathbf{7 0})$ & Comic $(\mathbf{n}=\mathbf{4 1 )}$ & Text $(\mathbf{n = 2 9 )}$ \\
\hline$\$ 0-\$ 9,999$ & $8(20 \%)$ & $11(38 \%)$ \\
\hline$\$ 10,000-\$ 24,999$ & $4(10 \%)$ & $4(13 \%)$ \\
\hline$\$ 25,000-\$ 49,999$ & $7(17 \%)$ & $4(13 \%)$ \\
\hline$\$ 50,000-\$ 74,999$ & $6(15 \%)$ & $1(3 \%)$ \\
\hline$\$ 75,000-\$ 99,999$ & $3(7 \%)$ & $1(3 \%)$ \\
\hline$\$ 100,000-\$ 124,999$ & $4(10 \%)$ & $2(7 \%)$ \\
\hline$\$ 125,000-\$ 149,999$ & $1(2 \%)$ & $1(3 \%)$ \\
\hline$\$ 150,000-\$ 174,999$ & $0(0 \%)$ & $1(3 \%)$ \\
\hline$\$ 200,000+$ & $1(2 \%)$ & $1(3 \%)$ \\
\hline Prefer not to say & $7(17 \%)$ & $4(13 \%)$ \\
\hline
\end{tabular}

Table 4

Comparison of Scores and Analysis Results

\section{DISCUSSION}

This analysis of 71 American 18- to 22-year-olds indicates that youth gain more knowledge when they view a comic panel of the Constitution than they do from reading the text of the document. Why is this important to political science faculty members and how might we apply this knowledge and use comics in the classroom?

As teachers and scholars, we are challenged to meet our students where they are to deliver content that many of us believe is essential for participatory democracy. We want our students to understand their political system so that they might spend a lifetime engaging with it. However, we do not want to "dumb down" disciplinary content or play to the lowest common denominator. That said, not all students enter college with the skills necessary to easily elucidate meaning from our foundational documents. Many faculty members teach at institutions with large populations of non-native ESL students. Faculty may recognize that not all students learn in the same way; offering multiple ways to connect with material supports classroom learning. We must ask ourselves if the virtue is in understanding the documents in their original form or their content. Primary documents may seem initially inaccessible but become more accessible over time, depending on how they are introduced in the classroom.

An example of how to use comics in the classroom is in the Palestinian American Youth Civic Engagement (PAYCE) program sponsored by the Stevens Initiative. This project included faculty from six universities (i.e., Al Quds University, An Najah National University, Drake University, Florida Agricultural and Mechanical University, University of New Hampshire, and University of Hartford), including two of this article's coauthors.

\begin{tabular}{|c|c|c|c|c|}
\hline & Pretest & Posttest & Difference & T Test \\
\hline Youth who saw the text $(n=29)$ & Mean=2.41 SD=1.02 & Mean $=2.55 \mathrm{SD}=1.12$ & +0.14 & $t(28)=0.68 p=0.2512$ \\
\hline Youth who saw the comic $(n=42)$ & Mean=2.48 SD=1.23 & Mean $=2.90 \mathrm{SD}=1.51$ & +0.43 & $t(41)=2.29 p=0.0136^{*}$ \\
\hline
\end{tabular}


Table 5

Comparison of Scores and Analysis Results by Question Content

\begin{tabular}{|c|c|c|c|c|}
\hline \multicolumn{5}{|c|}{ Question One: Supreme Court } \\
\hline & Pretest & Posttest & Difference & T Test \\
\hline Youth who saw the text $(n=29)$ & Mean $=0.21 \mathrm{SD}=0.41$ & Mean $=0.17 \mathrm{SD}=0.38$ & -0.04 & $t(28)=-0.37 p=0.643$ \\
\hline Youth who saw the comic $(n=42)$ & Mean $=0.33 \mathrm{SD}=0.48$ & Mean $=0.36 \mathrm{SD}=0.48$ & +0.03 & $t(41)=0.30 p=0.384$ \\
\hline \multicolumn{5}{|c|}{ Sum of Questions Two, Three, and Four: Congressional Duties } \\
\hline & Pretest & Posttest & Difference & T Test \\
\hline Youth who saw the text $(n=29)$ & Mean $=1.66 \mathrm{SD}=0.90$ & Mean $=1.79 \mathrm{SD}=1.08$ & +0.13 & $t(28)=0.72 p=0.237$ \\
\hline Youth who saw the comic $(n=42)$ & Mean $=1.64 \mathrm{SD}=1.03$ & Mean $=1.95 \mathrm{SD}=1.12$ & +0.31 & $t(41)=1.87 p=0.034^{*}$ \\
\hline \multicolumn{5}{|c|}{ Question Five: President } \\
\hline & Pretest & Posttest & Difference & T Test \\
\hline Youth who saw the text $(n=29)$ & Mean $=0.55 \mathrm{SD}=0.51$ & Mean $=0.59 \mathrm{SD}=0.50$ & +0.04 & $t(28)=0.30 p=0.384$ \\
\hline Youth who saw the comic $(n=42)$ & Mean $=0.50 \mathrm{SD}=0.51$ & Mean $=0.60 \mathrm{SD}=0.50$ & +0.10 & $t(41)=1.00 p=0.1616$ \\
\hline
\end{tabular}

In PAYCE, paired classes engage students in learning and cross-culturally sharing information about civics and political engagement. Comics are only one component of the PAYCE program, which uses technology to bring American and Palestinian students together to create comics and record podcasts and to engage in synchronous and asynchronous virtual exchange. Comics were chosen for the program because of their value in supporting communication, particularly with non-native ESL speakers.

The comic assignment in PAYCE asks students to first read the foundational documents and then create them in comic form to share a visual depiction with partner classes. This assignment is an extension of learning that does not simply present the visual images; it also asks students to create these comics themselves. For example, US students translate the text of the Declaration of Independence and Constitution into comics and share the results with their Palestinian counterparts. (Appendix D is a curriculum plan for using this assignment in class.)

The PAYCE curriculum is one way that visual learning may be implemented in the classroom to empower student learning. Viewing or creating comics allows students to be immersed in these documents, building knowledge by puzzling out their meaning. In this way, the PAYCE assignment illustrates what Keogh and Naylor (1999) found important about concept cartoons-not the image itself but rather how it aids discussion and inquiry.

\section{FUTURE WORK}

Whereas the results of this study are promising, it also is true that more research is needed to understand the influence of visual images on student learning. In the future, we want to include both a larger sample and a longer survey. Although this is not a matched sample, the groups are roughly comparable. An improved study would include a larger sample to better match respondents' characteristics to ensure that the only difference is their exposure to the text or comic. In addition, a future study should include several images incorporating different components of the Constitution and additional questions to indicate knowledge gained about the executive and judicial branches as well as the legislative branch.

\section{CONCLUSION}

Our results show that gains in knowledge from exposure to comics of the Constitution are both greater and statistically significant when compared to reading the text. This supports the hypothesis that comics help some learners connect with and understand the material. Professors of political science may find that comics in the classroom improve student understanding, providing a gateway to comprehension of foundational political documents.

\section{SUPPLEMENTARY MATERIAL}

To view supplementary material for this article, please visit https://doi.org/10.1017/S1049096519001008

\section{ACKNOWLEDGMENTS}

The Department of Politics, Economics, and International Studies in the College of Arts and Sciences at the University of Hartford provided support for this study. We are grateful for insightful comments of two anonymous reviewers. More about the PAYCE program is available at http://paycestories.org. $=$

\section{REFERENCES}

Akamca, Güzin Özyilmaz, A. Murat Ellez, and Hülya Hamurcu. 2009. "Effects of Computer-Aided Concept Cartoons on Learning Outcomes." Procedia-Social and Behavioral Sciences 1 (1): 296-301.

Baumgartner, Jody C. 2008. "Polls and Elections: Editorial Cartoons 2.o: The Effects of Digital Political Satire on Presidential Candidate Evaluations." Presidential Studies Quarterly 38 (4): 735-58.

Birisci, Salih, Mustafa Metin, and Mehmet Karakas. 2010. "Pre-Service Elementary Teachers' Views on Concept Cartoons: A Sample from Turkey.” Middle East Journal of Scientific Research 5 (2): 91-97.

CAST. 2019. "About Universal Design for Learning." Available at www.cast.org.

Center for Information and Research on Civic Learning and Engagement. 2016. "Young Voters in the 2016 General Election." Available at https://civicyouth.org/ full-analysis-young-voters-in-the-2016-general-election.

Clover, Darlene. 200o. "Community Arts as Environmental Education and Activism: A Labour and Environment Case Study." Convergence 33 (4): 19-30.

Curtis, David J. 2011. "Using the Arts to Raise Awareness and Communicate Environmental Information in the Extension Context." Journal of Agricultural Education and Extension 17 (2): 181-94

Curtis, David J., Nick Reid, and Ian Reeve. 2014. "Towards Ecological Sustainability: Observations on the Role of the Arts." S.A.P.I.E.N.S. 7 (1): 1-15. 
Dewhurst, Marit. 2011. "Where Is the Action? Three Lenses to Analyze Social Justice Art Education.” Equity \& Excellence in Education 44 (3): 364-78.

Dougherty, Beth K. 2002. "Comic Relief: Using Political Cartoons in the Classroom." International Studies Perspectives 3 (3): 258-70.

Frey, Nancy, and Douglas Fisher. 2008. Teaching Visual Literacy: Using Comic Books, Graphic Novels, Anime, Cartoons, and More to Develop Comprehension and Thinking Skills. Thousand Oaks, CA: Corwin Press.

Graham, Mark A. 2007. "Art, Ecology and Art Education: Locating Art Education in a Critical Place-Based Pedagogy." Studies in Art Education: A Journal of Issues and Research 48 (4): 375-91.

Hallett, Terry L., and Geraldine Faria. 2006. "Teaching with Multimedia: Do Bells and Whistles Help Students Learn?" Journal of Technology in Human Services 24 (2-3): 167-79

Hosler, Jay, and K. B. Boomer. 2011. "Are Comic Books an Effective Way to Engage Nonmajors in Learning and Appreciating Science?" CBE-Life Sciences Education $10(3): 309-17$

Kabapinar, Filiz. 2005. "Effectiveness of Teaching via Concept Cartoons from the Point of View of Constructivist Approach." Educational Sciences: Theory $\mathcal{E}$ Practice 5 (1): 135-46.

Keogh, Brenda, and Stuart Naylor. 1999. "Concept Cartoons, Teaching and Learning in Science: An Evaluation." International Journal of Science Education $21(4): 431-46$

Lawrence, Randee Lipson. 2005. "Knowledge Construction as Contested Terrain: Adult Learning through Artistic Expression.” New Directions for Adult $\mathcal{E}$ Continuing Education 107: 3-11

LeCompte, Karon N., and Michelle Bauml. 2012. "Artful Rights: Using Images to Teach the First Amendment." Social Studies Research \& Practice (Board of Trustees of the University of Alabama) 7 (2): 102-12.

Mayer, Richard E. 1997. "Multimedia Learning: Are We Asking the Right Questions?" Educational Psychologist 32 (1): 1-19.

Millgate House Education. 2014. "Learn Chemistry." The Royal Society of Chemistry. Available at www.rsc.org/learn-chemistry/resource/resoooo1881/ science-concept-cartoons-rusting?cmpid=CMPoooo5896.

Owens, Katharine A. 2016. "Captioning Political Cartoons from Different Perspectives as a Tool for Student Reflection.” In Learner-Centered Teaching Activities for
Environmental and Sustainability Studies, ed. Loren B. Byrne, 301-306. New York: Springer.

Park, Jin Seo, Dae Hyun Kim, and Min Suk Chung. 2011. "Anatomy Comic Strips." Anatomical Sciences Education 4 (5): 275-79.

Schreiner, Mary B., Cynthia D. Rothenberger, and Janae Sholtz. 2013. "Using Brain Research to Drive College Teaching: Innovations in Universal Course Design.” Journal on Excellence in College Teaching 24 (3): 29-50.

Schulz, Wolfram, John Ainley, Julian Fraillon, David Kerr, and Bruno Losito. 2010. ICCS 2009 International Report: Civic Knowledge, Attitudes, and Engagement among Lower-Secondary School Students in 38 Countries. Amsterdam, The Netherlands: International Association for the Evaluation of Educational Achievement.

Sloam, James. 2008. "Teaching Democracy: The Role of Political Science Education." British Journal of Politics and International Relations 10 (3): 509-24.

Survey Monkey Audience. 2019. "How We Find Survey Participants around the World." Available at www.surveymonkey.com/mp/find-survey-participants.

Tatalovic, Mico. 2009. "Science Comics as Tools for Science Education and Communication: A Brief, Exploratory Study.” Journal of Science Communication $8(4): 1-17$

Toh, Tin Lam. 2009. "Use of Cartoons and Comics to Teach Algebra in Mathematics Classrooms." Mathematics of Prime Importance 1 (May): 230-39.

Torney-Purta, Judith, Rainer Lehmann, Hans Oswald, and Wolfram Schulz. 2001. Citizenship and Education in Twenty-Eight Countries: Civic Knowledge and Engagement at Age Fourteen. Amsterdam, The Netherlands: IEA Secretariat.

Ulbig, Stacy. 2009. "Engaging the Unengaged: Using Visual Images to Enhance Students' 'Poli Sci 101' Experience." PS: Political Science \& Politics 42 (2): 385-91.

Ulbig, Stacy. 2010. "A Picture Is Worth What? Using Visual Images to Enhance Classroom Engagement." International Journal of Instructional Media 37 (2): 185-201.

Williams, Rachel Marie-Crane. 2008. "Image, Text, and Story: Comics and Graphic Novels in the Classroom." Art Education 61 (6): 13-19.

Wylie, Caitlin Donahue, and Kathryn A. Neeley. 2016. "Learning Out Loud (LOL): How Comics Can Develop the Communication and Critical-Thinking Abilities of Engineering Students." Proceedings of the 2016 American Society for Engineering Education Annual Conference. Salt Lake City, UT. 